\title{
BMJ Open Healing journey: a qualitative analysis of the healing experiences of Americans suffering from trauma and illness
}

\author{
John Glenn Scott, ${ }^{1,2}$ Sara L Warber, ${ }^{3,4}$ Paul Dieppe, ${ }^{4}$ David Jones, ${ }^{5}$ \\ Kurt C Stange $6,7,8,9,10$
}

To cite: Scott JG, Warber SL, Dieppe $\mathrm{P}$, et al. Healing journey: a qualitative analysis of the healing experiences of Americans suffering from trauma and illness. BMJ Open 2017;7:e016771. doi:10.1136/ bmjopen-2017-016771

- Prepublication history for this paper is available online. To view these files, please visit the journal online (http://dx.doi. org/10.1136/bmjopen-2017016771).

Received 15 March 2017 Revised 10 June 2017 Accepted 10 July 2017
CrossMark

For numbered affiliations see end of article.

Correspondence to John Glenn Scott; john.glenn.scott@gmail.com, j.scott@nvrh.org

\section{ABSTRACT}

Objectives To elucidate pathways to healing for people having suffered injury to the integrity of their function as a human being.

Methods A team of physician-analysts conducted thematic analyses of in-depth interviews of 23 patients who experienced healing, as identified by six primary care physicians purposefully selected as exemplary healers. Results People in the sample experienced healing journeys that spanned a spectrum from overcoming unspeakable trauma and then becoming healers themselves to everyday heroes functioning well despite ongoing serious health challenges. The degree and quality of suffering experienced by each individual is framed by contextual factors that include personal characteristics, timing of their initial or ongoing wounding in the developmental life cycle and prior and current relationships. In the healing journey, bridges from suffering are developed to healing resources/skills and connections to helpers outside themselves. These bridges often evolve in fits and starts and involve persistence and developing a sense of safety and trust. From the iteration between suffering and developing resources and connections, a new state emerges that involves hope, selfacceptance and helping others. Over time, this leads to healing that includes a sense of integrity and flourishing in the pursuit of meaningful goals and purpose.

Conclusion Moving from being wounded, through suffering to healing, is possible. It is facilitated by developing safe, trusting relationships and by positive reframing that moves through the weight of responsibility to the ability to respond.

\section{INTRODUCTION}

As medicine moves away from the Cartesian reductionism that considers patients as collections of organ systems and deposits of diseases, ${ }^{1}$ there has been much interest in how medical professionals can foster healing. ${ }^{2}$ The word 'healing' comes from the Old English haelan meaning 'whole' and alludes to a process that brings wholeness in physical, emotional, intellectual, social and spiritual aspects of self. ${ }^{3}$ There are several definitions of healing in the medical literature. Csordas describes healing as a

\section{Strengths and limitations of this study}

This is one of few studies to examine healing from the patient perspective.

- Qualitative analysis done by a diverse team.

- This model may give guidance and hope to people experiencing illness and suffering.

- Because participants were selected for their experience of healing, they are likely to not be representative of ill people in general.

- It is possible that the path to healing is affected by sex, race, ethnicity and a host of other factors that were not apparent in our small sample. Thus, our findings cannot be used to generalise about the effects of demography, time, place or culture.

transformational change. ${ }^{4}$ Egnew talks of transcending suffering. ${ }^{5}$ Kirmayer describes it as a journey from feeling ill to wellness. ${ }^{6}$ Hsu and colleagues ${ }^{5}$ emphasise recovery and regaining a sense of balance and peace. Cassel defines healing as "making whole again. ${ }^{2} 7$ Scott et al describe it as being cured when possible, reducing suffering when cure is not possible and finding meaning beyond the illness experience. ${ }^{8}$ All of these definitions have in common the idea of recovering a sense of integrity and wholeness after experiencing illness and suffering. This synthesis is the definition of healing that we used in our analysis.

In 2001, the Institute of Medicine included the 'development of continuous healing relationships' as their first priority in improving the quality of medicine. ${ }^{9}$ The nursing literature has been particularly important in theoretical development and empirical studies related to nurse-patient relationships, especially with regards to caring. ${ }^{10} 11$ Studies on healing relationships between doctors and patients have focused on interviews with physicians $^{71213}$ or patients ${ }^{14}$ or both. ${ }^{58}$ While this focus on healing relationships between health professionals and patients is useful for 
health professionals, what is missing from this literature is a description of the experience of people who are ill and how they manage to find healing. Eric Cassels describes the dilemma we continue to face: “...from all this, we would have to conclude that it is not known what the basis of healing is, but also there is little doubt that there really is something called healing."

Although there is a literature on patients' experience of healing, it consists primarily of anecdotal reports (pathographies) by individuals describing their personal experiences with illness and healing. ${ }^{15}$ There are a few systematic qualitative studies of healing from the patient perspective in the nursing literature, but all of these describe healing from specific illnesses. ${ }^{16-20}$ Verhoef and Mulkins did a qualitative analysis of the healing experiences of patients with a diversity of diseases, but this was limited to patients attending integrative clinics that included complementary and alternative practitioners. $^{21}$

Because of a continued need for deeper understanding of the process of healing from the point of view of the person experiencing it, this study was undertaken to explore pathways to healing for people who have been wounded by serious illness and/or life events and who access care through the conventional health system.

\section{METHODS}

We conducted a qualitative analysis of transcripts of in-depth interviews with 23 people who had experienced healing. This was a secondary analysis of data originally collected by Scott $e t a l$ in their study of healing relationships between doctors and patients. ${ }^{8}$ That study included physician interviews as well and focused on how doctors and patients experienced their relationships with each other. In this study we used only the patient interviews, which contained rich descriptions of pathways to healing.

\section{Sampling strategy}

As described in more detail by Scott et $a l^{8}$ physicians believed to be exemplars in developing and maintaining healing relationships were purposefully selected based on an assessment of publications, such as books about patient relationships, reputation by peer nomination and awards such as Family Doctor of the Year. Each physician was interviewed and also asked to identify three to six adult patients whom they perceived to have experienced healing. These patients were contacted personally by the physician and asked if they were willing to take part; they constitute the sample for the current study. This sampling strategy was designed to maximise the probability of finding the phenomenon we wished to study, that is, people who had experienced healing. One physician did not contact any of his patients. This was the only refusal in the study. The interviewer had no relationship with any of the participants with the exception of five patients from his previous practice.

\section{Interviews}

Participants were contacted by telephone or email to schedule interviews. At the interview meeting, participants were informed that the researcher was a physician and that the purpose of the research was to study healing. After obtaining written informed consent, the first author conducted face-to-face in-depth interviews, alone with the participants according to a semistructured interview guide $^{\mathrm{i}}$ that contained several grand tour questions ${ }^{22}$ designed to elicit healing stories from the participants. The interview guide included questions about healers other than physicians as well as questions about what patients bring to healing relationships. Because the interviews were analysed iteratively, the interview guide underwent modifications through the first few interviews. Interviews lasted 1 to 3 hours and were conducted at places of the participants' choosing, most commonly in their homes, but some at their physician's office and some at restaurants or other venues chosen by the participants. There were no repeat interviews. The interviews were recorded and transcribed. The interviewer also recorded field notes after each interview. Transcripts were checked for accuracy and were imported into qualitative analysis software, Atlas-ti. ${ }^{23}$ Because of logistical difficulties, it was not possible to return the transcripts to the participants for comment and correction. The Robert Wood Johnson Medical School Institutional Review Board approved the original study ${ }^{8}$ and determined that further research using deidentified transcripts would not require institutional review board review.

A total of 23 participants, identified by their physicians as people who had experienced healing, were interviewed. Their ages ranged from 30 to 86 at the time of interview (mean 58); 14 were female and 9 male; 17 were White, 4 Hispanic and 2 Black; 14 were of high socioeconomic status, 4 mid and 5 low.

Participants had a complex mixture of medical, psychological and social issues, which included: myocardial infarction, congestive cardiac failure, inflammatory bowel disease, cancer, diabetes, chronic pain, HIV infection, substance abuse, obsessive-compulsive disorder, incest and sexual abuse. Most of the interviewees had more than one problem.

\section{Analysis}

The current analysis team consisted of a family physician with 21 years' experience in private practice as well as extensive experience in qualitative research and analysis (JGS), two practising family physicians from large academic medical centres, both of whom have qualitative research experience (KCS) and (SLW), a rheumatologist/health services researcher from an academic medical centre in the UK who is undertaking research on healing (PD) and a practising family physician from the west

${ }^{i}$ See http://www.annfammed.org/content/suppl/2008/07/07/6.4.315. DC1/Scott_App_1-2.pdf 
coast of the USA who was instrumental in developing the concepts, knowledge base and tools for the clinical application of functional medicine ${ }^{24}$ (DJ).

Analysis proceeded iteratively, ${ }^{22}$ using a combination of editing $^{25}$ and immersion/crystallisation ${ }^{22}$ approaches. These qualitative methods are a modification of a grounded theory approach to analysis ${ }^{26}$ that has been well documented by Crabtree and Miller. ${ }^{27}$ Initial preliminary coding was done by the first author. Over several months, the analysis team individually read the interviews. The interviews were then discussed as a group via a number of conference calls. One member served as primary analyst for each interview, producing an initial summary and thematic analysis supported by representative quotations and refining this case analysis as the group discussion produced confirming or disconfirming data and additional interpretations.

Case studies were analysed to identify common themes. Finally, at a 3-day intensive retreat, the analysis team extensively discussed these themes, referring back to the original data and case summaries for confirming and disconfirming evidence. This analysis was used to develop a model of pathways to healing. The data were deidentified, so we were unable to have participants comment on the analysis.

\section{Data saturation}

Interviews were analysed iteratively by the original research team. ${ }^{8}$ Interviews continued until the team found no more new themes emerging from the interviews. At that point, the team determined that data saturation had been reached and the interviews were terminated.

\section{FINDINGS}

\section{The healing journeys}

Analyses revealed that healing was not an isolated event that happened at a particular point in time. Rather, healing typically took place in fits and starts over an extended period of time. This process was not linear and not predictable. The path to healing was different for each person. The metaphor of a journey emerged as an apt description of this process, because that was how the participants talked about their experiences of healing. These journeys spanned a spectrum from overcoming unspeakable trauma (sexual abuse by a parent for example) and then becoming healers themselves (therapist, social worker for example) to everyday heroes functioning despite ongoing health challenges (eg, functioning in family and daily life despite enduring chronic pain from inflammatory bowel disease). During their journeys all the participants experienced suffering, defined as the experience of distress when the intactness or integrity of the person is threatened. ${ }^{2}$

\section{Major themes that describe the healing journey Connections outside oneself}

Connection to others was an essential part of all the healing journeys. As participant P1.1 who had severe depression and an eating disorder, said, "Once I started connecting with people, I started healing". This connection was with other patients while she was hospitalised.

People experiencing healing developed relationships with many kinds of helpers. Relationships with health professionals were among these but were not necessarily any more important to the healing journey than other kinds of helpers, which included family members, friends, spirituality and their God, pets, support groups, administrators, case workers and supervisors.

\section{Safety and trust}

To connect to helpers, it was essential for people to feel safe in those relationships and able to trust that the person would be a helper and not a barrier to healing.

Persons whose wounds included a violation of trust were especially careful about testing the safety of new relationships. Participant E3.4, a survivor of incest tested the boundaries of relationships to make sure they were safe. She said,

I always felt like I pushed boundaries but I needed them really badly. I needed to make sure nobody was going to violate them, but I needed first to know where they are and I needed to figure out if they were comfortable.

When safety and trust had been established, people were able to connect with helpers.

The nature of the behaviours of helpers that fostered healing ranged from small acts of kindness to unconditional love.

Participant E3.4 was abused by her father and uncle but found unconditional love from her maternal grandmother:

She was a very good nurturer matriarch who sort of on the outside you couldn't tell she was the matriarch.

But she really was. She was running everything. And she was just so unconditional positive love for me and all my cousins.

The love from her grandmother helped mitigate the pain of the abuse at home.

Participant J.4 was socially isolated from people partly because he was ashamed of his HIV infection. He received unconditional love, however, from his dogs:

It's one of the most important things that I've ever felt. It's like a love that the animal shows. And you can get that from people too, but not near as often.

The love he felt from his dogs helped him cope with his social isolation and depression.

Participant, P2.3 in the depths of drug abuse and HIV infection, had a transformative religious experience.

I heard God talk to me. I felt his presence. And I think that's what keeps me in recovery.

Participant P2.3 was also grateful for small acts of kindness. She related this story about the office venipuncturist: 
Anytime I have to give blood..., any place else it's like... They're going to see my track marks and they're going to say, “Oh, my God!" like you're being judged. But I don't feel that here. I have a good relationship with the venipuncturist too, the lady that draws the blood. She says "Oh, you have such good veins now." So they're so accepting and they're so happy for you that you are doing well.

This is an example of the importance of compassion in every interaction with people in the healthcare system.

Participant E4.3 experienced sexual abuse as a child and ended up in a bad marriage as well. She participated in a support group in which she experienced love and healing:

We had 40 participants on a weekend, plus the team people...like 50 people every single time. And incredible healing to be able to say this and to have these people accept me and love me and care about me.

This was a self-help group and was not led by a medical professional.

Participant E4.1 had severe congestive heart failure, untreated because of his Christian Science background. When he finally called a physician, who made a home visit, he said,

I went from the darkest despair to bright hope. And that was because of him and what he said to me and how he said it and just the caringness of him.

This physician, rather than being judgemental about participant E4.1's's previous lack of care, accepted him as he was and gave him hope.

Participant E3.3 found another way to connect outside himself. He found healing in creating art. He said,

When I'm either taking pictures with my camera, framing them, painting and sculpturing, that's my best. That's the best healer for me.

This story illustrates that, although there are common features, every healing journey is unique.

\section{Acquiring resources and skills}

Making connections enabled participants to acquire and refine resources and skills that were essential in their healing journey. People also brought their own personal strengths to the journey.

A particularly important skill was the ability to reframe-that is to look at suffering through a different lens. Participant E3.4, who was struggling with her history of sexual abuse by family members, said of her therapist,

I think I kept trying to convince him I was crazy. And he kept saying, "No you're not crazy." He didn't pathologise, a lot of things he saw as a reaction to some atrocious circumstances, rather than like the way you wouldn't necessarily say a Vietnam Vet was crazy. You'd say they are responding like you'd expect to extraordinary circumstances.

Participant E3.4 learnt this skill from her therapist, and then was able to use it herself. She said,

And I think the meaning I was holding onto was ... not that this happened because, but maybe a way to sort of put a positive spin on something that you can't ever imagine to put a positive spin on would be for me to help other survivors and that would...I almost started feeling stronger, like having this experience and survived it made me better than I would have been otherwise.

She reframed the experience of abuse as something that made her stronger rather than damaging her.

Participant P2.1, who had HIV infection said,

I'm not the only one who have this problem. A lots, millions of people, you know. Little babies, little kids. They don't have nothing to do with that. They have it, you know. I guess I have to live. And that was one of the things that used to keep me real stable.

His ability to reframe his illness as something that could happen to anyone made him able to realise that he was not to blame for his illness.

Another resource that people acquired or refined during their healing journey was choose to be positive-that is to have some optimism about their situation. For some, being positive was a trait they already had. For example, participant E1.1, who had diabetes, said,

Yes, you have to be positive. And like I said, it's everything. I'm very positive. Honestly, I'm a very positive lady.

This was a personality trait, but still was a resource that helped her in her healing journey.

Some people, however, learnt to choose to be positive through their helping connections. Participant P2.1 with his HIV infection was in despair and ready to die, but by connecting to his sister he was able to change his attitude. After his sister visited him in the hospital and told him she wanted him to be there for her wedding he said,

I always not even thinking negative, You always gotta think positive. You always gotta think how beautiful life is.

His sister's positive attitude gave him hope and allowed him to learn to be positive.

A third essential resource that people acquired or refined was the ability to take an appropriate amount of responsibility for their healing journeys. They participated actively in the process of healing. Once again, some participants already had developed this skill, and some acquired or refined it from their helpers. Participant E4.3.2, who was sexually abused as a child, described the degree of participation required: 
You need a lot of energy and a lot of work...it takes a lot of work. It doesn't just happen. It's not like a magic wand. 'I'll go to the right doctor and boom.

He understood that he had to participate in his healing.

Participant J.3, who lost a child to SIDS, said,

I have to contribute just as much as every therapist and then some, because I have to do it for myself. And if I'm not helping myself who the heck should? I'd better take care of myself and I've got to try and discern when something is necessary to be tended to or when something is not necessary to be tended to and know to differentiate the two.

Again, this participant illustrates taking appropriate responsibility for healing.

Some people needed help in taking an appropriate amount of responsibility. For example, participant P2.3 was lost in the depths of substance abuse. She was taking so many pills that she went to sleep in the middle of a conversation in which she was asking for more pills from the psychiatrist at the methadone clinic. She describes what happened then:

So, when I woke up... all the administrators from the programme were in the office. And they said, "If you don't get help, we're kicking you off the clinic." So, they said, "You have a week." And they found me a place and I went through detox off the pills. And when I got off the pills, because I was so clouded up... when I got off the pills, it was like a rebirth. And I sort of had like a spiritual awakening and stuff came to me... and ever since then...I still struggled a little bit, but I started getting dedicated, I started making meetings.

The clinic administrators gave her a chance to accept responsibility rather than dismissing her from the clinic immediately.

\section{Emergent characteristics \\ Persistence}

People did not simply progress through this sequence and experience healing. The healing journey was a recursive, back and forth process. They found helpers, used the skills/resources that those helpers provided, found other helpers that provided more resources and used those skills and resources. As this process continued, people experienced a gradual amelioration of their suffering. Although many despaired at times, all demonstrated the quality of persistence-they refused to give up. Participant P2.3 said,

And when I couldn't see the light on the other side, I still struggled every day to live. I still struggled every day to live.

As people struggled through their recursive healing journeys, several common characteristics began to emerge, which we document here with illustrative quotations:

Hope

The expectation that there can be an end to present suffering. Participant E3.1, who suffered from Chrohn's disease, said,

I think gradually I realised that I was going to feel better. I did have days when I actually didn't vomit, when I did feel better. And I think gradually I came to believe that maybe I could have a normal life again.

Although slowly and fitfully, hope did emerge for this participant.

\section{Self-acceptance}

The ability to accept oneself as a valuable person. Participant P2.1 said,

I'm really proud of myself. I think that now I still want to live. I don't want to die, and I really love myself a lot. I have a lot of comfort in myself.

His self-acceptance emerged partly from his understanding that he was not to blame for his illness.

\section{Desire to help others}

Understanding that suffering gives the strength and experience to help others in similar situations. Participant P1.1 adopted a special needs child. She said,

So, I think that's what helped me plug along. I just don't feel like... I always feel like I have to feel that I can do something for somebody else, not just always done for me. I didn't want to feel just passive; I could be doing something for somebody else too.

\section{Healing}

The re-establishment of a sense of integrity and wholeness. We found we could best understand healing as an emergent property of the complex healing journeys of individuals in the context of their lives. None of these people were cured of their illnesses, but all developed a sense of integrity and wholeness despite ongoing pain or other symptoms. To one degree or another, they were all able to transcend their suffering and in some sense to flourish. Participant E3.1 expressed it this way:

I think the gradual realization through my stress class and everything was the acceptance of the fact that it wasn't going to go away. It did not go away, but it did not have to mean the end of my life in terms of never being able to do anything I enjoyed ever again, or being able to eat anything I enjoyed ever again.

Her Crohn's disease was not cured, but she was no longer defined by her illness.

Participant P2.3 became a social worker. She said

Yeah, and it's just like just connections, like the healing process is about like connecting to other people, like 


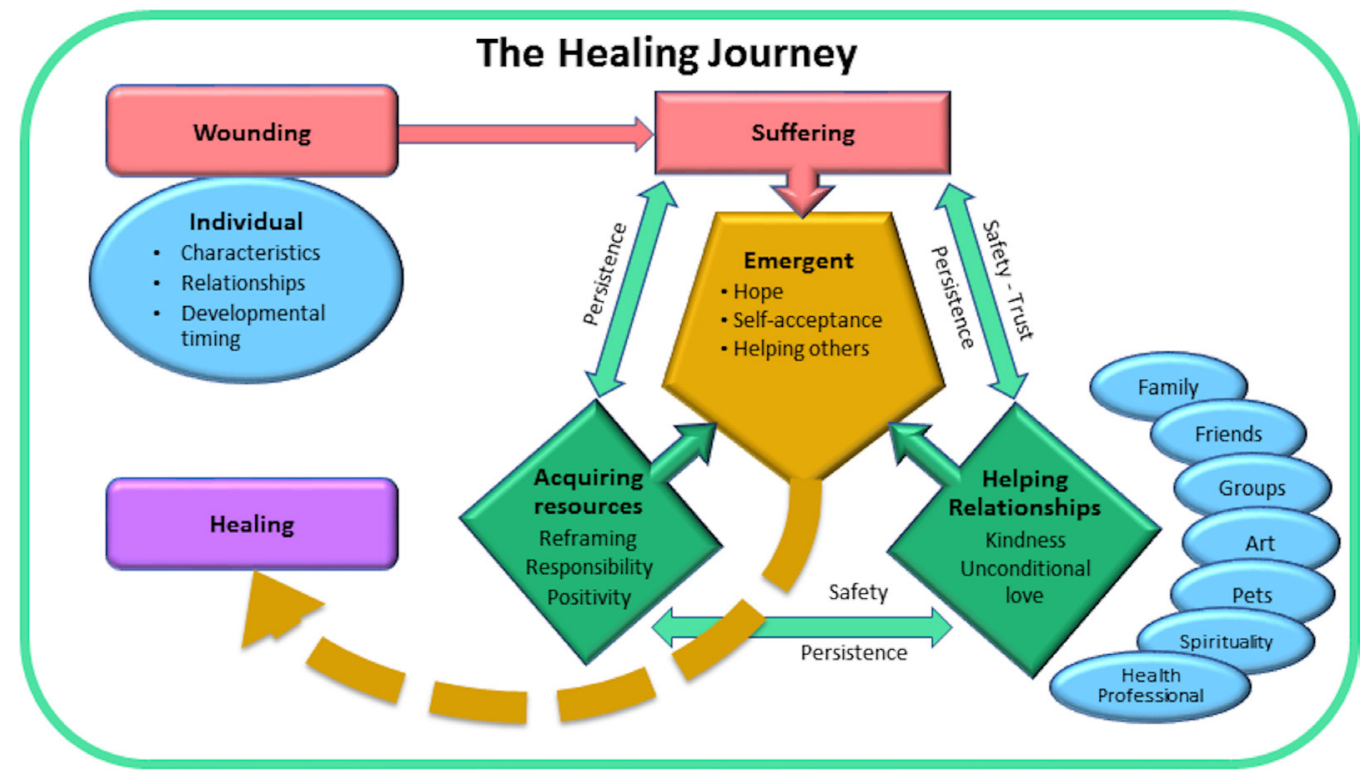

Figure 1 Healing Journey Model.

you're not by yourself in this world. ...So, it's like we're so attached; yet we're so disconnected. And I think that that's the mission is for connectedness, for wholeness.

For her, healing and a sense of wholeness emerged from her connections with others.

\section{Model}

From these themes we developed a model, illustrated in figure 1. Moving clockwise from the upper left, the model shows that an initial physical/emotional wounding leads to suffering. The manifestation and degree to which the initial wound causes suffering is dependent on people's personal characteristics, relationships and stage in the developmental life course.

People's healing journey is facilitated by persistence and through developing a sense of safety and trust. This allows the person to make new connections to relationships with helping others and to acquire important resources, such as reframing, responsibility and positivity. Bridges develop between the various connections made and resources that are acquired. Over time, these relationships and resources foster hope, self-acceptance and the desire to help others, leading, in fits and starts, to the emergence of a sense of wholeness and integrity that constitutes healing.

\section{DISCUSSION}

This study has demonstrated that the path to healing is not a simple, linear process, but rather, a complex journey that involves suffering, connecting with others and acquiring needed resources. The journey requires persistence and the ability to find trustworthy relationships with others. As this recursive process continues, emergent personal properties of hope, self-acceptance and helping others develop. Gradually a sense of integrity and wholeness develops despite continuing symptoms of the original insult or illness.

Our work adds a new perspective to the existing healing literature, most of which focuses on relationships between healthcare professionals and their patients. This is exemplified by Jackson in the nursing literature. ${ }^{10}{ }^{28}$ Egnew developed his definition of healing by analysing interviews with physicians ${ }^{7}$ and Hsu et al developed their definition of healing in focus groups with physicians, nurses, clinical staff and patients. ${ }^{5}$ Churchill et alinterviewed patients, but their focus was on qualities of physicians that patients felt contributed to their healing. ${ }^{14}$ In contrast to much of this literature, our study focuses on how people experience the progression from illness and suffering to healing, something that has been reported in personal stories but has received little research attention. Relationships with healthcare professionals were a part of that process but often not the most important part. This finding is in accord with sociological studies, such as the seminal work of Arthur Kleinman ${ }^{29}$ who pointed out that all healthcare takes place in a social context, involving three sectors: the popular sector that includes help from family and friends, the folk sector, that includes accessing therapies not recognised by the mainstream and the professional sector. Our work emphasises the complex and overlapping interactions of these sectors in helping people along their healing journeys.

Recently, psychiatry has put emphasis on the need for recovery, even if the disease is not cured, within their 'recovery movement ${ }^{30}$ and one recent review suggested that the key processes involved were connectedness, hope and optimism, identity, finding meaning and empowerment. ${ }^{31}$ Again, this is in accord with our findings.

This study expands on the previous work of Scott et $a l^{8}$ which focused on the nature of the healing relationship between physicians and their patients but noted 
that other kinds of relationships facilitated healing. The present study is unusual, as we have focused on the experiences of 'patients' rather than professionals-a group of people on the slow journey from illness and suffering to healing. Relationships with healthcare professionals were important but were only part of the process. Connections within and beyond the self and relationships with other people, animals or creativity were similarly important.

Acquiring new resources and skills is something that is stressed by the recovery movement, which tries to empower people to find the resources they need. ${ }^{30} 31$ The narratives that we analysed suggest that in conventional, disease-orientated, primary and secondary care settings, people had to find their own way towards both acquiring the necessary skills and resources and to making meaning of their problems. They had to accept responsibility for themselves, reframe their experiences and choose positivity to make progress towards healing.

Only when they had made some appropriate connections, acquired necessary skills and persevered, could healing emerge, along with hope, self-acceptance and a desire to help others. Even then, our informants often described continued suffering, but they were now able to function effectively: the key outcome of healing processes in the view of Cassel. ${ }^{2}$ This concept is also in accord with the Aristotelian ideas of flourishing and eudaimoniathe idea that we should all live life to fulfil our capabilities (which vary according to constitution and illness) for the sake of the whole community as well as ourselves. ${ }^{32}$ Research on patients with chronic illness has shown that this concept remains relevant to their ability to function well. $^{33}$

There are limitations to our analysis. The patients in this study were purposefully chosen by their physicians as likely to have experienced healing, and, as such, are likely to not be representative of ill people in general-they were purposefully selected to have rich and deep experience of the phenomena we were trying to elucidate. The resulting model, therefore, is relevant to bringing hope to people who are suffering-hope that healing is possible. The model also brings a sufficiently detailed description of the healing process that it may be useful to individuals struggling to heal or to people attempting to help them through the healing journey. We do not presume, however, that healing always happens or is even always possible. It is not our intention to contribute to a "cult of positivity ${ }^{34}$ to disparage those who have not experienced a healing journey as we have described it. It is possible that the path to healing is affected by sex, race, ethnicity and a host of other factors that were not apparent in our small sample. Thus, our findings cannot be used to generalise about the effects of demography, time, place or culture. Although the interviews for this study were conducted 10 years ago, it is unlikely that the experience of illness, suffering and healing is any different today than it was then. Interview data have the inherent limitation of dealing with perceptions of respondents' experiences of events rather than observations of events themselves, but in this study the perceptions of respondents was exactly what we wanted to capture and individual interviews were a reasonable approach. Our analysis uses an interpretivist paradigm. ${ }^{35}$ Researchers who adhere to other qualitative research paradigms, particularly the positivist paradigm may find fault with our analysis approach. Our interpretation of these data is inevitably influenced by our life experience. Others might view the data differently and come to different conclusions. The validity of our analysis, however, is enhanced by the training and experience of the analysis team, reflexivity (reflecting on our own experiences) and searching the data for disconfirming evidence after we identified themes.

The findings of our study, which describes the journey of healing may give hope to people suffering from illness and may suggest some strategies for them to use to begin their own healing journey. Programmes designed to serve patients may use the findings to align their offerings and staff training with these stages of the healing journey. Health professionals should look at these findings not as minimising their role in helping to facilitate healing, but rather putting that role in the larger context of their patients' healing journey. Every person in a healthcare setting from the physician to the janitor can help or hinder patients on their healing journey. Our findings also suggest that health professionals may want to help patients recruit other helpers, such as family members, coworkers or supervisors to facilitate their healing journeys. Understanding the pathways from wounding and suffering to the emergence of healing can inform and encourage individuals' healing journey and may help others to be supportive of their fellow travellers in fostering healing.

\section{Author affiliations}

${ }^{1}$ Department of Family Medicine, Northeastern Vermont Regional Hospital, Corner Medical, Lyndonville, Vermont, USA

${ }^{2}$ Department of Community and Family Medicine, Dartmouth Geisel School of

Medicine, Hanover, New Hampshire, USA

${ }^{3}$ Department of Family Medicine, University of Michigan Medical School, Ann Arbor, Michigan, USA

${ }^{4}$ University of Exeter Medical School, Exeter, UK

${ }^{5}$ The Institute for Functional Medicine, Federal Way, Washington, USA

${ }^{6}$ Departments of Family Medicine and Community Health, Case Western Reserve University, Cleveland, Ohio, USA

${ }^{7}$ Department of Epidemiology and Biostatistics, Case Western Reserve University, Cleveland, Ohio

${ }^{8}$ Department of Sociology, Case Western Reserve University, Cleveland, Ohio ${ }^{9}$ Case Comprehensive Cancer Center, Case Western Reserve University, Cleveland, Ohio

${ }^{10}$ Cleveland Clinical and Translational Science Collaborative, Case Western Reserve University, Cleveland, Ohio

Acknowledgements The authors are grateful to the physicians and patients who participated in this study. KS, DJ and PD are scholars of the The Institute of Integrative Health (TIIH.org) and would like to acknowledge their support. TIIH also provided financial help towards the 3-day data analysis retreat at which all authors were present.

Contributors JGS was the interviewer for all the subject interviews. He coordinated and participated in the conference calls for data analysis. He was present for and participated in the 3-day retreat for final data analysis. He wrote the first draft of the paper and contributed to all subsequent drafts including the final 
one. SLW participated in the data analysis via conference calls and was present at the 3-day retreat for final data analysis. She added her input to multiple drafts of the paper and she prepared the final figure of the healing journey model. PD participated in the data analysis via conference calls and was present at the 3-day retreat for final data analysis. He added his input to multiple drafts of the paper and wrote the initial draft of the introduction section. KCS participated in the data analysis via conference calls and was present at the 3-day retreat for final data analysis. He added his input to multiple drafts of the paper and wrote the initial draft of the abstract. DJ participated in the data analysis via conference calls and was present at the 3-day retreat for final data analysis. He added his input to multiple drafts of the paper and was instrumental in helping to refine the healing journey model. All authors gave final approval of this version and all agree to be accountable for all aspects of the work.

Funding As noted, the authors received some funding for meeting expenses from the Institute for Integrative Health, Baltimore, Maryland. DJ also received some meeting support from the Institute for Functional Medicine. KCS also received some support from a Clinical Research Professorship from the American Cancer Society.

Competing interests None declared.

Provenance and peer review Not commissioned; externally peer reviewed.

Data sharing statement The deidentified interview transcripts are available from the corresponding author upon request.

Open Access This is an Open Access article distributed in accordance with the Creative Commons Attribution Non Commercial (CC BY-NC 4.0) license, which permits others to distribute, remix, adapt, build upon this work non-commercially, and license their derivative works on different terms, provided the original work is properly cited and the use is non-commercial. See: http://creativecommons.org/ licenses/by-nc/4.0/

(C) Article author(s) (or their employer(s) unless otherwise stated in the text of the article) 2017. All rights reserved. No commercial use is permitted unless otherwise expressly granted.

\section{REFERENCES}

1. Pellegrino ED. The internal morality of clinical medicine: a paradigm for the ethics of the helping and healing professions. J Med Philos $2001 ; 26: 559-79$.

2. Cassell EJ. The nature of suffering and the goals of medicine. 2nd ed. New York: Oxford University Press, 2004.

3. Warber SL, Bruyere RL, Weintrub K, et al. A consideration of the perspectives of healing practitioners on Research Into Energy healing. Glob Adv Health Med 2015;4:72-8.

4. Csordas TJ, Kleinman A. The therapeutic process. In: Johnson TM Sargent CF, eds. Medical Anthropology: contemporary Theory and Method. New York, NY: Praeger Publishers, 1990.

5. Hsu C, Phillips WR, Sherman KJ, et al. Healing in primary care: a vision shared by patients, physicians, nurses, and clinical staff. Ann Fam Med 2008;6:307-14.

6. Kirmayer LJ. The cultural diversity of healing: meaning, metaphor,and mechanism. Heart Views 2013;14:39-40.

7. Egnew TR. The meaning of healing: transcending suffering. Ann Fam Med 2005;3:255-62.

8. Scott JG, Cohen D, Dicicco-Bloom B, et al. Understanding healing relationships in primary care. Ann Fam Med 2008;6:315-22.

9. Crossing the Quality Chasm. A New Health System for the $21 \mathrm{st}$ Century: Institute of Medicine, Committee on Quality of Health Care in America, 2001.
10. Jackson C. Healing ourselves, healing others: first in a series. Holist Nurs Pract 2004;18:67-81.

11. Swanson K. What is known about caring in nursing science: a literary meta-analysis. In: Hinshaw AS, Feetham S, Shaver JLF, eds. Handbook of clinical nursing research. Thousand Oaks, Calif: Sage Publications, 1999:31-60.

12. Churchill LR, Schenck D. Healing skills for medical practice. Ann Intern Med 2008;149:720-4.

13. Schenck D, Churchill LR. Healers: extraordinary clinicians at work. New York: Oxford University Press, 2012

14. Churchill LR, Fanning JB, Schenck D. What patients teach: the everyday ethics of health care.

15. Hawkins AH. Reconstructing illness: studies in pathography. 2nd ed. West Lafayette, Ind: Purdue University Press, 1999.

16. Isaak CA, Stewart DE, Mota NP, et al. Surviving, healing and moving forward: journeys towards resilience among Canadian Cree adults. Int J Soc Psychiatry 2015;61:788-95.

17. Flasch P, Murray CE, Crowe A. Overcoming abuse: a phenomenological investigation of the journey to Recovery from Past Intimate Partner Violence. J Interpers Violence 2015.

18. Tseng YF, Chen $\mathrm{CH}$, Wang $\mathrm{HH}$. Taiwanese women's process of recovery from stillbirth: a qualitative descriptive study. Res Nurs Health 2014;37:219-28.

19. Foster JM, Hagedorn WB. Through the eyes of the wounded: a narrative analysis of children's sexual abuse experiences and recovery process. J Child Sex Abus 2014;23:538-57.

20. West C, Stewart L, Foster K, et al. The meaning of resilience to persons living with chronic pain: an interpretive qualitative inquiry. $J$ Clin Nurs 2012;21(9-10):1284-92.

21. Verhoef MJ, Mulkins A. The healing experience-how can we capture it? explore. Jul 2012:8:231-6.

22. Borkan JM. Immersion/Crystallization. In: Crabtree BF, Miller WL, Doing qualitative research. 1999. Second ed. Newbury Park: SAGE Publications:179-94.

23. Berlin: Scientific Software Development. Atlas.ti (computer program). Version 5, 2003-2005.

24. Insitute for functional medicine. What is functional medicine? https:// http://www.functionalmedicine.org/What_is_Functional_Medicine/ AboutFM/ (Accessed January 24, 2016).

25. Addison RB. A Grounded Hermanuetic Editing Approach. Crabtree BFM WM, ed. Doing qualitative research. 1. Second ed. Thousand Oaks, CA: Sage Publicationw, 1999. Vol.

26. Strauss AL, Corbin JM. Basics of qualitative research: techniques and procedures for developing grounded theory. 2nd ed. Thousand Oaks: Sage Publications, 1998.

27. Crabtree BF, Miller WL. Doing qualitative research. 2nd ed. Thousand Oaks, Calif: Sage Publications, 1999.

28. Jackson SW. The wounded healer. Bull Hist Med 2001;75:1-36.

29. Kleinman A. The illness narratives: suffering, healing, and the human condition. New York: Basic Books, 1988.

30. Jaeger M, Hoff P. Recovery: conceptual and ethical aspects. Curr Opin Psychiatry 2012;25:497-502.

31. Leamy M, Bird V, Le Boutillier C, et al. Conceptual framework for personal recovery in mental health: systematic review and narrative synthesis. Br J Psychiatry 2011;199:445-52.

32. Aristotle. The Nichomachean Ethics. New York: The Bobs-Merrill Company, 1962.

33. Swift TL, Ashcroft RE, Tadd W, et al. Living well through chronic illness: the relevance of virtue theory to patients with chronic osteoarthritis. Arthritis Rheum 2002;47:474-8.

34. Ehrenreich B, Ehrenreich J. Health care and social control. Soc Policy 1974;5:26-40.

35. Cohen DCB. Qualitative research guidelines project. 2016. htpp:// http://www.qualres.org/index.html 